\title{
Time-varying serum albumin levels and all- cause mortality in prevalent peritoneal dialysis patients: a 5-year observational study
}

Na Hao ${ }^{1}$, Ben-Chung Cheng ${ }^{2}$, Hong-Tao Yang ${ }^{1}$, Chien-Hsing Wu ${ }^{2}$, Yang-Yang Lei ${ }^{1}$, Mei-Chen Chao ${ }^{3}$, Pei-Ying Wang ${ }^{3}$, Li-Chueh $\mathrm{KuO}^{3}$, Sin-Hua Moi ${ }^{4}$, Cheng-Hong Yang ${ }^{4,5}$ and Jin-Bor Chen ${ }^{2 *}$ (D)

\begin{abstract}
Background: In this study, we investigated the association of time-varying serum albumin levels with mortality over a 5-year period in one cohort of patients undergoing long-term peritoneal dialysis (PD) therapy.

Methods: The participants in this study enrolled 302 patients who underwent long-term PD at a single PD center in Taiwan. We reviewed medical records from 2011 to 2015 retrospectively. Time-averaged albumin level and serum albumin reach rate (defined as the percentage of serum albumin measurements that reached $\geq 3.5 \mathrm{~g} / \mathrm{dL}$ ) were applied as the predictor variables in the first 2 years (2011-2012). All-cause mortality was used as the outcome variable in the subsequent 3 years (2013-2015). Hazard function of all-cause mortality in the study participants was examined by using Cox proportional hazard regression models

Results: Patients with different albumin reach rates $(75-<100 \%, 50-<75 \%, 1-<50 \%)$ did not exhibit a significantly increased risk for all-cause mortality. Patients with a $0 \%$ albumin reach rate exhibited a significantly increased risk for all-cause mortality (hazard ratio [HR] 7.59, 95\% confidence interval [CI], 2.38-24.21) by fully adjusted analysis. Patients with time-averaged albumin levels of $<3.5 \mathrm{~g} / \mathrm{dL}$ (HR 15.49, 95\% Cl 1.74-137.72) exhibited a higher risk for all-cause mortality than those with serum albumin levels $\geq 4.0 \mathrm{~g} / \mathrm{dL}$.
\end{abstract}

Conclusions: This study demonstrated that higher serum albumin reach rates and higher time-averaged serum albumin levels are associated with a lower mortality rate over a 5-year period among patients undergoing longterm PD.

Keywords: Albumin, Mortality, Peritoneal dialysis

\section{Background}

The number of patients undergoing peritoneal dialysis (PD) is increasing worldwide. It is estimated that there are more than 272,000 PD patients, accounting for $11 \%$ of the dialysis population [1]. Despite advances in dialysis technology, dialysis patients still develop multisystem metabolic disorders, leading to high and accelerated mortality rates [2]. Among the metabolic disorders,

\footnotetext{
* Correspondence: chenjb1019@gmail.com

${ }^{2}$ Division of Nephrology, Department of Internal Medicine, Kaohsiung Chang Gung Memorial Hospital and Chang Gung University College of Medicine, No.123 Dapi Road, Niaosong District, Kaohsiung City 83301, Taiwan Full list of author information is available at the end of the article
}

protein-energy wasting is an emerging concern for nephrologists. There has been a consensus that nutritional intervention improves nutritional parameters and survival rates [3].

Serum albumin level is an important observation index for assessing nutritional status, and its effect on mortality in dialysis patients has been examined [4-9]. Several clinical circumstances have been reported to result in low serum albumin levels, including inadequate dialysis [10], fluid overload, inflammatory and infectious diseases [11, 12], co-morbidities [13], and taste changes [14]. Low serum albumin levels are associated with high mortality rates in dialysis patients. One study found that

(c) The Author(s). 2019 Open Access This article is distributed under the terms of the Creative Commons Attribution 4.0 International License (http://creativecommons.org/licenses/by/4.0/), which permits unrestricted use, distribution, and 
a persistently low serum albumin level for 6 months was associated with all-cause and cardiovascular mortalities in the subsequent months [8]. However, this study has scarce data on the time-varying levels of serum albumin and its association with long-term survival in dialysis patients.

The aim of this cohort study was to investigate the long-term effect of serum albumin levels on the survival of prevalent PD patients. We measured 2 predictor variables, target albumin reach rates and time-averaged albumin levels, over 2 years to predict the subsequent 3year all-cause mortality.

\section{Methods}

\section{Participants}

The records of 555 prevalent PD patients who were tracked from 2011 to 2015 at Kaohsiung Chang Gung Memorial Hospital in Taiwan were reviewed. We excluded 253 patients because of incomplete demographic and laboratory data, and 302 patients were considered eligible for the survival analysis. The exclusion criteria were as follows: (1) age < 18 years, (2) incomplete clinical information, and (3) transfer to other hospital or kidney transplantation. The requirement for patient consent was waived by the Institutional Review Board of Chang Gung Memorial Hospital (document no. 201800595B0), in accordance with the principles of the Declaration of Helsinki. In keeping with the retrospective data review regulations of the Committee on Human Research of Kaohsiung Chang Gung Memorial Hospital, signed informed consent from the study participants was not required.

\section{Laboratory measurements}

The participants enrolled in the study underwent monthly hematological and biochemical examinations in the outpatient clinic. Baseline values that were collected and measured in January 2011 included hemoglobin $(\mathrm{Hb})$, albumin, potassium (K), corrected serum calcium $(\mathrm{Ca})$, phosphate $(\mathrm{P})$, intact parathyroid hormone (iPTH), alkaline phosphate (ALP), cholesterol, triglyceride, 24-h urine volume, total $\mathrm{Kt} / \mathrm{V}$, weekly urine creatinine clearance rate $(\mathrm{Ccr})$, total weekly $\mathrm{Ccr}$, and protein catabolic rate normalized using actual body weight. The formula for calculating the protein catabolic rate was $10.76 \times\left\{\left[\left(\mathrm{UV} \times \mathrm{U}_{\mathrm{BUN}}+\mathrm{DV} \times \mathrm{D}_{\mathrm{BUN}}\right) / 1440+1.46\right] / \mathrm{BSA}\right\} \times$ 1.73 , where UV is the urine volume (L), DV is the dialysate volume $(\mathrm{L}), \mathrm{U}_{\mathrm{BUN}}$ is the urine blood urea nitrogen (BUN), $\mathrm{D}_{\mathrm{BUN}}$ is the dialysate BUN, and BSA is the body surface area. All blood samples were analyzed using commercial kits and an auto-analyzer (Hitachi 7600210; Hitachi Ltd., Tokyo, Japan). Albumin level was measured using the bromocresol green method; the normal range in the hospital was $3.5-5.2 \mathrm{~g} / \mathrm{dL}$. iPTH was measured using a chemiluminescence immunoassay (Siemens Healthcare Diagnostics Inc., Tarry Town, NY, USA). The parameters of standard peritoneal equilibration tests measured in January 2011 were collected as baseline data.

\section{Stratified serum albumin levels}

We used the time-averaged albumin level and serum albumin reach rate (target level: $3.5 \mathrm{~g} / \mathrm{dL}$ ) in 2011-2012 as the predictor variables. All-cause mortality in 20132015 was used as the outcome variable. The timeaveraged albumin level was the average of the 24-month serum albumin level in 2011-2012. We defined serum albumin reach rate in the first 2 years (2011-2012) as the percentage of albumin measurements that reached $\geq 3.5 \mathrm{~g} / \mathrm{dL}$. Two serum albumin stratifications were used for analyses. We stratified the albumin reach rate into 5 groups depending on the serum albumin levels that reached $3.5 \mathrm{~g} / \mathrm{dL}$ among the 24-month measurements. A $100 \%$ albumin reach rate indicated that all 24 monthly serum albumin measurements had reached $3.5 \mathrm{~g} / \mathrm{dL}$, and $0 \%$ indicated that none of the 24 monthly serum albumin measurements had reached $3.5 \mathrm{~g} / \mathrm{dL}$. Subsequently, we divided the participants into 2 groups according to the percentage of monthly serum albumin measurements that reached $\geq 3.5 \mathrm{~g} / \mathrm{dL}$ over the first 2-year (2011-2012) follow-up period. Patients with $\geq 75 \%$ serum albumin measurements reaching $\geq 3.5 \mathrm{~g} / \mathrm{dL}$ were classified as the higher rate group, whereas those with < $75 \%$ serum albumin measurements reaching $\geq 3.5 \mathrm{~g} / \mathrm{dL}$ were indicated as the lower rate group.

\section{Outcome measures}

The outcome measures included the association between the serum albumin reach rate and time-averaged albumin levels in the first 2 years, with the subsequent 3-year all-cause mortality.

\section{Statistical analysis}

The baseline characteristics and clinical variables of the study population were grouped according to 24 months albumin rate reached at $3.5 \mathrm{~g} / \mathrm{dL}$ and summarized as frequency (percentage) or mean (standard deviation). The difference between groups was estimated using independent two-sample t-test, chi-squared test, or Fisher's exact test. The Cox proportional hazard regression model was used to determine the association between different albumin categories by using 24-month serum albumin measurements and all-cause mortality. A $P$ value of $<0.05$ was considered statistically significant. Stata version 11.0 (StataCorp. 2009. Stata Statistical Software: Release 11. College Station, TX: StataCorp LP.) was used for all statistical analyses. 


\section{Results}

A total of 302 patients were analyzed. During the 5-year period, 205 patients had high albumin levels, whereas 97 patients had low albumin levels. Older patients had lower serum albumin reach rates. Data of blood parameters showed that patients with lower albumin reach rates exhibited significantly lower values of $\mathrm{Hb}$, albumin, $\mathrm{P}$, and dialysis $\mathrm{Kt} / \mathrm{V}$ than did those with higher albumin reach rates. However, ALP was significantly higher in patients with lower albumin reach rates (Table 1 ).

Table 2 shows the distribution of the study population in different albumin classes (measured using 2-year serum albumin levels) and mortality rates based on stratified serum albumin levels. The trend of all-cause mortality showed a parallel increase with decreased serum albumin reach rates. A similar trend was observed in time-averaged serum albumin levels.

Table 3 shows the association between different albumin stratification levels (measured using the serum albumin levels for the first 24 months) and all-cause mortality over the subsequent 3 years based on Cox regression analysis. Adjusted analysis showed that the risk of all-cause mortality in the participants increased parallel to low albumin reach rates. Participants who had a $0 \%$ albumin reach rate had the highest statistically significant risk for all-cause mortality (hazard ratio [HR] 15.49, 95\% confidence interval [CI] 1.74-137.72). Stratified time-averaged serum albumin levels showed a similar trend. Participants with time-averaged albumin levels $<3.5 \mathrm{~g} / \mathrm{dL}$ exhibited a 15.49 -fold increased rate of all-cause mortality as compared with those with the reference level $(\geq 4.0 \mathrm{~g} / \mathrm{dL})$.

\section{Discussion}

Serum albumin is commonly considered to be a strong predictor of mortality in dialysis patients [5, 6, 9, 15-17]. Prior studies considered time-varying changes in serum albumin levels in examining the relationship of serum albumin level with mortality in dialysis patients $[9,17]$. In a 19-month study, investigators found that serum

Table 1 Baseline characteristics and clinical features of the study population according to different albumin levels ( $N=302)$

\begin{tabular}{|c|c|c|c|c|c|}
\hline \multirow[t]{3}{*}{ Variable } & \multicolumn{4}{|c|}{24 months albumin rate reached $3.5(\mathrm{~g} / \mathrm{dL})$} & \multirow[t]{3}{*}{$P$-value } \\
\hline & \multicolumn{2}{|c|}{ Higher rate $(n=205)$} & \multicolumn{2}{|c|}{ Lower rate $(n=97)$} & \\
\hline & Mean & SD & Mean & SD & \\
\hline Dialysis vintage (years) & 8.07 & 2.95 & 7.58 & 3.49 & 0.207 \\
\hline Age (years) & 50.22 & 12.65 & 54.75 & 14.38 & 0.006 \\
\hline Gender (n, \%) & & & & & 0.241 \\
\hline Male & 95 & 46.34 & 38 & 39.18 & \\
\hline Female & 110 & 53.66 & 59 & 60.82 & \\
\hline Diabetes Mellitus (n, \%) & 31 & 15.12 & 20 & 20.62 & 0.234 \\
\hline \multicolumn{6}{|l|}{ Blood analysis } \\
\hline $\mathrm{Hb}(\mathrm{g} / \mathrm{dL})$ & 10.70 & 1.41 & 10.06 & 1.43 & $<0.001$ \\
\hline Albumin (g/dL) & 3.97 & 0.30 & 3.45 & 0.40 & $<0.001$ \\
\hline $\mathrm{K}(\mathrm{meq} / \mathrm{L})$ & 4.30 & 0.75 & 4.18 & 0.71 & 0.181 \\
\hline $\mathrm{Ca}(\mathrm{mg} / \mathrm{dL})$ & 9.29 & 0.75 & 9.40 & 0.85 & 0.270 \\
\hline$P(\mathrm{mg} / \mathrm{dL})$ & 5.46 & 1.36 & 5.12 & 1.08 & 0.033 \\
\hline iPTH $(\mathrm{pg} / \mathrm{mL})^{\mathrm{a}}$ & 100 & $(41.6-377)$ & 93 & $(31.6-203)$ & 0.594 \\
\hline $\operatorname{ALP}(U / L)^{a}$ & 88 & $(67-116)$ & 99 & $(73-156)$ & 0.018 \\
\hline Cholesterol (mg/dL) ${ }^{a}$ & 181 & $(161-205)$ & 178 & $(158-197)$ & 0.157 \\
\hline Triglyceride $(\mathrm{mg} / \mathrm{dL})^{\mathrm{a}}$ & 133 & $(91-196)$ & 115 & $(82-193)$ & 0.213 \\
\hline Urine volume $24 \mathrm{HR}(\mathrm{mL})^{\mathrm{a}}$ & 600 & $(400-920)$ & 600 & $(400-720)$ & 0.252 \\
\hline $\mathrm{Kt} / \mathrm{N}$ & 2.14 & 0.36 & 2.00 & 0.40 & 0.004 \\
\hline Weekly urine $\mathrm{Ccr}^{\mathrm{a}}$ & 14.43 & $(9.92-20.73)$ & 14.43 & $(13.93-14.425)$ & 0.499 \\
\hline Weekly total $\mathrm{Ccr}^{\mathrm{a}}$ & 59.01 & $(50.74-69.1)$ & 59.01 & $(50.94-65.25)$ & 0.475 \\
\hline nPCR (g/kg/day) & 1.08 & 0.25 & 1.06 & 0.23 & 0.476 \\
\hline
\end{tabular}

Patients aged $<18$ years $(n=2)$ were excluded

${ }^{a}$ Median (interquartile range)

$P$-values of categorical variables were estimated using the $x^{2}$ test, and those for continuous variables were estimated using the 2-sample t-test

$H b$ hemoglobin, $K$ potassium, $C a$ corrected serum calcium, $P$ phosphate, $i P T H$ intact parathyroid hormone, ALP alkaline phosphate, $C c r$ creatinine clearance rate, $n P C R$ normalized protein catabolic rate 
Table 2 Different albumin categories based on 24-month serum albumin measurements in the study population

\begin{tabular}{|c|c|c|c|c|}
\hline \multirow[t]{2}{*}{ Albumin category } & \multicolumn{2}{|l|}{ Total } & \multicolumn{2}{|c|}{ All-cause mortality } \\
\hline & $\bar{n}$ & $\%$ & $\overline{n^{a}}$ & $\%$ \\
\hline \multicolumn{5}{|c|}{ Albumin rate reached $3.5(\mathrm{~g} / \mathrm{dL})$} \\
\hline 100 & 115 & 38.08 & 8 & 6.96 \\
\hline 75 to $<100$ & 90 & 29.80 & 8 & 8.89 \\
\hline 50 to $<75$ & 35 & 11.59 & 6 & 17.14 \\
\hline 1 to $<50$ & 40 & 13.25 & 7 & 17.50 \\
\hline 0 & 22 & 7.28 & 11 & 50.00 \\
\hline \multicolumn{5}{|c|}{ Albumin rate reached $3.5(\mathrm{~g} / \mathrm{dL})$} \\
\hline Higher rate (75 to 100$)$ & 205 & 67.88 & 16 & 7.80 \\
\hline Lower rate $(0$ to $<75$ ) & 97 & 32.12 & 24 & 24.74 \\
\hline \multicolumn{5}{|c|}{ Time-averaged serum albumin } \\
\hline$\geq 4$ & 47 & 15.56 & 1 & 2.13 \\
\hline 3.5 to $<4$ & 181 & 59.93 & 20 & 11.05 \\
\hline$<3.5$ & 74 & 24.50 & 19 & 25.68 \\
\hline
\end{tabular}

albumin levels measured before PD initiation was better at predicting mortality than albumin levels measured at PD initiation [17]. Our previous study demonstrated that hemodialysis patients with lower time-averaged serum albumin levels had higher mortality rates over 5 years [9]. This study investigated the relationship of target serum albumin reach rates and time-averaged albumin levels with mortality in PD patients over a 5-year period.
PD patients with lower target serum albumin reach rates and lower time-averaged albumin levels demonstrated a higher all-cause mortality. The results demonstrated the long-term effect of serum albumin levels on the mortality risk of PD patients and showed that a sustained serum albumin level is crucial for maintaining survival benefit in prevalent PD patients.

In this study, we set the minimum standard for serum albumin level at $3.5 \mathrm{~g} / \mathrm{dL}$. This criterion was based on the lower normal limits of our laboratory tests and the standard of the National Health Insurance Authority of Taiwan (http://sc-drtw/news/104/010603.htm; http://scdrtw/news/104 /01/01060301.pdf). This cutoff level is lower than the recommended level of $3.8 \mathrm{~g} / \mathrm{dL}$ by the International Society of Renal Nutrition and Metabolism [3]. We acknowledge that the lower target serum albumin level used in this study may underestimate the percentage of lower serum albumin level in our cohort. However, because our study uses time-varying serum albumin levels, we hypothesized that the target serum level set in our study could not interfere with the trend of albumin changes during the observation period. Nevertheless, further studies are needed to validate the optimal serum albumin level for PD patients.

In this study, the $\mathrm{Kt} / \mathrm{V}$ values of participants with high albumin reach rates were significantly higher than those with low albumin reach rates. Multivariate regression analysis showed that baseline serum albumin levels had a positive correlation with total $\mathrm{Kt} / \mathrm{V}$ and a negative

Table 3 Associations between different albumin categories based on 24-month serum albumin measurements and all-cause mortality in the study population

\begin{tabular}{|c|c|c|c|c|}
\hline \multirow[t]{3}{*}{ Albumin category } & \multicolumn{4}{|c|}{ All-cause mortality } \\
\hline & \multirow{2}{*}{$\begin{array}{l}\text { Deaths } \\
\text { (n) }\end{array}$} & Unadjusted & Adjusted (demographic) ${ }^{a}$ & Adjusted $^{\mathrm{b}}$ \\
\hline & & HR $(95 \% \mathrm{Cl})$ & $\mathrm{HR}(95 \% \mathrm{Cl})$ & $\mathrm{HR}(95 \% \mathrm{Cl})$ \\
\hline \multicolumn{5}{|c|}{ Albumin rate reached $3.5(\mathrm{~g} / \mathrm{dL})$} \\
\hline 100 & 8 & Reference & Reference & Reference \\
\hline 75 to $<100$ & 8 & $1.29(0.48-3.43)$ & $1.2(0.45-3.23)$ & $0.9(0.28-2.84)$ \\
\hline 50 to $<75$ & 6 & $2.61(0.9-7.51)$ & $2.32(0.79-6.76)$ & $2.56(0.8-8.24)$ \\
\hline 1 to $<50$ & 7 & $2.66(0.97-7.35)$ & $2.33(0.82-6.6)$ & $2.85(0.85-9.6)$ \\
\hline 0 & 11 & $11.04(4.43-27.5)$ & $5.63(1.97-16.09)$ & $7.59(2.38-24.21)$ \\
\hline \multicolumn{5}{|c|}{ Albumin rate reached $3.5(\mathrm{~g} / \mathrm{dL})$} \\
\hline Higher rate (75 to 100$)$ & 16 & Reference & Reference & Reference \\
\hline Lower rate $(0$ to < 75$)$ & 24 & $3.59(1.91-6.76)$ & $2.66(1.35-5.24)$ & $3.57(1.66-7.65)$ \\
\hline \multicolumn{5}{|c|}{ Time-averaged serum albumin } \\
\hline$\geq 4$ & 1 & Reference & Reference & Reference \\
\hline 3.5 to $<4$ & 20 & $5.33(0.72-39.74)$ & $4.11(0.55-30.8)$ & $5.81(0.72-47.12)$ \\
\hline$<3.5$ & 19 & $14.12(1.89-105.46)$ & $6.95(0.91-53.27)$ & $15.49(1.74-137.72)$ \\
\hline
\end{tabular}

Univariate and multivariate Cox proportional hazard regression models

Adjusted (demographic) ${ }^{a}$, adjusted for demographic variables including dialysis vintage, age, sex, and diabetes mellitus Adjusted $^{\mathrm{b}}$, adjusted for all demographic and laboratory variables

$H R$ hazard ratio, $\mathrm{Cl}$ confidence interval 
correlation with total weekly Ccr. We also found that weekly urine Ccr did not have a statistically significant correlation with the baseline serum albumin level. It is generally believed that adequate dialysis has a significant impact on the outcome of PD patients [18]. Our previous study demonstrated that insufficient dialysis could lead to worsening nutritional status [19]. Minimum dialysis adequacy indices have been recommended to maintain optimal dietary nutrient intake to avoid protein-energy wasting in dialysis patients $[3,20]$. However, studies that directly examine the effect of increased dialysis dose on nutritional parameters in dialysis patients are scarce. Our study has a cross-sectional design; hence, we could not examine the cause-effect relationship between dialysis adequacy and albumin level. We believe that it is worthy to conduct a study investigating the association between dialysis dose and nutritional parameters in PD patients in the future.

The present study has several limitations. First, its cross-sectional retrospective design does not allow for examining the effect of immortal time. Therefore, we used the serum albumin levels in the first 2 years to examine their effect on mortality in the subsequent 3 years. A similar method was also applied by other relevant studies $[8,9,21]$. Second, our study did not include other possible factors affecting nutritional parameters, such as economic and social status, comorbidities, hospitalizations, and dialysis protocols. Third, the sample size was very small resulting in a wide confidence interval in the significance findings (HR 15.49, 95\% CI 1.74-137.72) and reduce the reliability of current findings. Hence, the results should be validated in a larger cohort study. On the other hand, this study has some strengths. First, our study is the first to use 2-year target serum albumin reach rate and time-average albumin level to examine the correlation with mortality in the next 3 years in prevalent PD patients. Second, the observation period was 5 years. Therefore, the long-term trend in serum albumin levels in prevalent PD patients was observed, and examination of the relationship between time-varying serum albumin levels and mortality was possible.

\section{Conclusions}

This study demonstrated that target serum albumin reach rate and time-averaged albumin levels were associated with all-cause mortality in prevalent PD patients. This result emphasizes the importance of serum albumin level as a surrogate predictor for mortality in PD patients.

\section{Abbreviations}

ALP: Alkaline phosphate; Ca: Corrected serum calcium; Ccr: Creatinine clearance rate; Cl: Confidence interval; Hb: Hemoglobin; HR: Hazard ratio; iPTH: Intact parathyroid hormone; K: Potassium; nPCR: Normalized protein catabolic rate; P: Phosphate; PD: Peritoneal dialysis

\section{Acknowledgements}

The authors thank the nurses in the peritoneal dialysis center for their dedication to data collection.

\section{Authors' contributions}

$\mathrm{NH}$ and $\mathrm{JBC}$ drafted the manuscript. JBC, BCC, and YYL conceived and designed the idea of this research. MCC and PYW collected the data. LCK critically reviewed and analyzed data. HTY and CHW performed English editing. MSH executed statistical analysis. CHY critically reviewed the statistical data. All authors read and approved the final manuscript.

\section{Funding}

Financial support of secretary process is covered by Tianjin Science and Technology Program (No.15ZXLCSY00020), Research Project of Tianjin Municipal Health Commission on key areas of TCM (2018004).

\section{Availability of data and materials}

All data supporting the study are presented in the manuscript or are available upon request from the corresponding author of this manuscript (Jin-Bor Chen, e-mail address: chenjb1019@gmail.com).

\section{Ethics approval and consent to participate}

This study was conducted with a waiver of patient consent approved by the Institutional Review Board of Kaohsiung Chang Gung Memorial Hospital (document no. 201800595B0) and conducted according to the Declaration of Helsinki. In keeping with the retrospective data review regulations of the Committee on Human Research of Kaohsiung Chang Gung Memorial Hospital, signed informed consent from the study participants was not required.

\section{Consent for publication}

Not applicable.

\section{Competing interests}

The authors declare that they have no competing interests.

\section{Author details}

${ }^{1}$ Division of Nephrology, First Teaching Hospital of Tianjin University of Traditional Chinese Medicine, 88 Chang Ling Rd, Xi Qing District, Tianjin, China. ${ }^{2}$ Division of Nephrology, Department of Internal Medicine, Kaohsiung Chang Gung Memorial Hospital and Chang Gung University College of Medicine, No.123 Dapi Road, Niaosong District, Kaohsiung City 83301, Taiwan. ${ }^{3}$ Peritoneal Dialysis Center, Division of Nephrology, Kaohsiung Chang Gung Memorial Hospital and Chang Gung University College of Medicine, No.123 Dapi Road, Niaosong District, Kaohsiung City 83301, Taiwan. ${ }^{4}$ Department of Electronic Engineering, National Kaohsiung University of Science and Technology, No. 415 Jiangong Road, Sanmin District, Kaohsiung City 80778, Taiwan. ${ }^{5}$ Ph. D. Program in Biomedical Engineering, Kaohsiung Medical University, No. 100, Shiquan 1st Road, Sanmin District, Kaohsiung City 807, Taiwan.

Received: 26 June 2018 Accepted: 23 June 2019

Published online: 10 July 2019

References

1. Li PK, Chow KM, Van de Luijtgaarden MW, Johnson DW, Jager KJ, Mehrotra $\mathrm{R}$, et al. Changes in the worldwide epidemiology of peritoneal dialysis. Nat Rev Nephrol. 2017;13:90-103.

2. de Mutsert R, Grootendorst DC, Axelsson J, Boeschoten EW, Krediet RT, Dekker FW. Excess mortality due to interaction between protein-energy wasting, inflammation and cardiovascular disease in chronic dialysis patients. Nephrol Dial Transplant. 2008;23:2957-64.

3. Ikizler TA, Cano NJ, Franch H, Fouque D, Himmelfarb J, Kalantar-Zadeh K, et al. Prevention and treatment of protein energy wasting in chronic kidney disease patients: a consensus statement by the International Society of Renal Nutrition and Metabolism. Kidney Int. 2013;84:1096-107.

4. Iseki K, Kawazoe N, Fukiyama K. Serum albumin is a strong predictor of death in chronic dialysis patients. Kidney Int. 1993:44:115-9.

5. Avram MM, Fein PA, Bonomini L, Mittman N, Loutoby R, Avram DK, et al. Predictors of survival in continuous ambulatory peritoneal dialysis patients: a five-year prospective study. Perit Dial Int. 1996;16(Suppl 1):S190-4. 
6. Jones $\mathrm{CH}$, Newstead CG, Wills EJ, Davison AM. Serum albumin and survival in CAPD patients: the implications of concentration trends over time. Nephrol Dial Transplant. 1997;12:554-8.

7. Lo WK, Tong KL, Li CS, Chan TM, Wong AK, Ho YW, et al. Relationship between adequacy of dialysis and nutritional status, and their impact on patient survival on CAPD in Hong Kong. Perit Dial Int. 2001;21:441-7.

8. Kalantar-Zadeh K, Kilpatrick RD, Kuwae N, McAllister CJ, Alcorn H Jr, Kopple $J D$, et al. Revisiting mortality predictability of serum albumin in the dialysis population: time dependency, longitudinal changes and populationattributable fraction. Nephrol Dial Transplant. 2005;20:1880-8.

9. Chen JB, Cheng BC, Yang CH, Hua MS. An association between time-varying serum albumin level and the mortality rate in maintenance haemodialysis patients: a five-year clinical cohort study. BMC Nephrol. 2016;17:117.

10. Owen WF Jr, Lew NL, Liu Y, Lowrie EG, Lazarus JM. The urea reduction ratio and serum albumin concentration as predictors of mortality in patients undergoing hemodialysis. N Engl J Med. 1993;329:1001-6.

11. Churchill DN, Taylor DW, Cook RJ, LaPlante P, Barre P, Cartier P, et al. Canadian hemodialysis morbidity study. Am J Kidney Dis. 1992;19:214-34.

12. Kaysen GA, Stevenson FT, Depner TA. Determinants of albumin concentration in hemodialysis patients. Am J Kidney Dis. 1997;29:658-68

13. Chan M, Kelly J, Batterham M, Tapsell L. Malnutrition (subjective global assessment) scores and serum albumin levels, but not body mass index values, at initiation of dialysis are independent predictors of mortality: a 10year clinical cohort study. J Ren Nutr. 2012;22:547-57.

14. Steiber AL. Clinical indicators associated with poor oral intake of patients with chronic renal failure. J Ren Nutr. 1999;9:84-8.

15. Yun T, Ko YE, Kim SJ, Kang DH, Choi KB, Oh HJ, et al. The additional benefit of weighted subjective global assessment (SGA) for the predictability of mortality in incident peritoneal dialysis patients: a prospective study. Medicine (Baltimore). 2017;96:e8421.

16. Gamba G, Mejia JL, Saldivar S, Pena JC, Correa-Rotter R. Death risk in CAPD patients. The predictive value of the initial clinical and laboratory variables. Nephron. 1993;65:23-7.

17. Sharma AP, Gupta A, Sharma RK, Agarwal DK, Sural S, Wardhe DJ. Does serum albumin at start of continuous ambulatory peritoneal dialysis (CAPD) or its drop during CAPD determine patient outcome? Adv Perit Dial. 2000;16:119-22.

18. Szeto CC, Lai KN, Wong TY, Law MC, Leung CB, Yu AW, et al. Independent effects of residual renal function and dialysis adequacy on nutritional status and patient outcome in continuous ambulatory peritoneal dialysis. Am J Kidney Dis. 1999;34:1056-64.

19. Chen JB, Lam KK, Su YJ, Lee WC, Cheng BC, Kuo CC, et al. Relationship between $\mathrm{Kt} / \mathrm{N}$ urea-based dialysis adequacy and nutritional status and their effect on the components of the quality of life in incident peritoneal dialysis patients. BMC Nephrol. 2012;13:39.

20. Blake PG, Bargman JM, Brimble KS, Davison SN, Hirsch D, McCormick BB, et al. Clinical practice guidelines and recommendations on peritoneal Dialysis adequacy 2011. Perit Dial Int. 2011;31:218-39.

21. Miskulin DC, Martin AA, Brown R, Fink NE, Coresh J, Powe NR, et al. Predicting 1 year mortality in an outpatient haemodialysis population: a comparison of comorbidity instruments. Nephrol Dial Transplant. 2004; 19:413-20.

\section{Publisher's Note}

Springer Nature remains neutral with regard to jurisdictional claims in published maps and institutional affiliations.

\section{Ready to submit your research? Choose BMC and benefit from:}

- fast, convenient online submission

- thorough peer review by experienced researchers in your field

- rapid publication on acceptance

- support for research data, including large and complex data types

- gold Open Access which fosters wider collaboration and increased citations

- maximum visibility for your research: over $100 \mathrm{M}$ website views per year

At BMC, research is always in progress.

Learn more biomedcentral.com/submissions 